\title{
DESENVOLVIMENTO INDUSTRIAL E MERCADO DE TRABALHO: contestação social e transformações recentes na produção siderúrgica na Amazônia Oriental
}

\author{
Roberto Martins Mancini* \\ Marcelo Sampaio Carneiro* *
}

\begin{abstract}
O artigo analisa os efeitos socioeconômicos de políticas governamentais de infraestrutura e de subsídios fiscais e financeiros (Programa Grande Carajás) que, a partir do final da década de 1970, ajudaram a implantar um polo industrial siderúrgico de produção de ferro-gusa voltado para a exportação, na Amazônia oriental maranhense. Um dos efeitos da criação desse polo siderúrgico foi o estabelecimento de um mercado de trabalho, que envolve trabalhadores metalúrgicos e florestais, em função da utilização de carvão vegetal como insumo da produção siderúrgica. Partindo da perspectiva das Redes de Produção Globais (RPGs), abordagem multicêntrica que enfatiza a ação de atores diversificados do mundo social na conformação de fenômenos econômicos, procuramos compreender o processo de configuração desse mercado de trabalho, destacando as transformações ocasionadas pela crise global de 2008 e o papel desempenhado por sindicatos, empresários e agentes estatais nesse processo.

Palavras-chave: Desenvolvimento industrial. Redes de produção globais. Mercado de trabalho. Crítica Social. Amazônia.
\end{abstract}

\section{INTRODUÇÃO}

A partir do final da década de 1970, um conjunto de políticas governamentais desencadeou a implantação de um polo siderúrgico na Amazônia maranhense, através de programas de desenvolvimento de infraestrutura de transporte mineral (Projeto Ferro Carajás) e incentivos fiscais e financeiros (Programa Grande Carajás). Tais políticas, para além das expectativas propaladas pelo discurso oficial, produziram transformações sociais e de reestruturação econômica nos territórios nos quais foram implantadas, influenciando a atuação de atores sociais locais, cujas ações fizeram parte da conformação da nova estruturação econômica regional, que passou a ser caracterizada pela presença de duas atividades principais: siderurgia e silvicultura com carvoejamento, para fins industriais.

\footnotetext{
* Universidade Federal do Maranhão (UFMA). Programa de Pós-graduação em Ciências Sociais.

Av. dos Portugueses, 1966. Bloco 6, Térreo, Sala 3. Bacanga. Cep: 65.080-805. São Luís - Maranhão - Brasil.

robertomancini89@hotmail.com

${ }^{\star *}$ Universidade Federal do Maranhão (UFMA). Programa de Pós-graduação em Ciências Sociais.

Av. dos Portugueses, 1966. Bacanga. Cep: 65.080-805. São

Luís - Maranhão - Brasil. marcelosc@uol.com.br
}

O desenvolvimento econômico induzido pelo Estado intervencionista (Fligstein, 2001) está aqui colocado numa perspectiva não valorativa, como um processo que provoca mudanças sociais e econômicas, sem deixar de considerar a forma como atores coletivos locais incorporam e compreendem essa indução a mudanças, passando a participar do processo de estruturação econômica e social. Aqui, estamos na mesma perspectiva de Santos (2010, p.130), para quem o "desenvolvimento econômico deve ser apreendido a partir da transformação das condições de produção, reprodução e representação de agentes e grupos econômicos e não econômicos, em situações concretas”.

O processo de mudança induzido pelo fomento governamental trouxe reverberações na conduta de atores sociais locais, que atuam através de repertórios de ação coletiva (Tarrow, 2009) e constroem uma crítica social (Boltanski; Chiapello, 2009) que confrontará a forma como os principais atores econômicos das cadeias da siderurgia, da silvicultura e do carvoejamento vêm atuando, ao longo dos últimos trinta anos, na Amazônia maranhense, tendo como polo principal o município de Açailândia (Carneiro, 2016). 
O movimento de estruturação econômica aqui descrito ocasionou a formação de um território produtivo caracterizado pela presença da produção de ferro-gusa (siderurgia primária) e da atividade de reflorestamento e carvoejamento, a ela subordinada. Outra característica importante dessa siderurgia, com repercussões importantes para seu desenvolvimento, é o fato de ela estar inserida em uma Rede de Produção Global (Henderson et al., 2011; Santos, 2011), vinculando-se, a montante, com a exploração de minério de ferro pela empresa Vale S/A, na Serra de Carajás, e, a jusante, com as siderúrgicas localizadas nos Estados Unidos, produtoras de aço e derivados, que, posteriormente, vendem seus produtos para grandes montadoras de automóveis, como Ford, General Motors, Nissan, Mercedes e BMW. (Greenpeace, 2012).

A abordagem das Redes de Produção Globais (RPGs) enfatiza uma perspectiva multicêntrica na medida em que percebe três tipos de "poder" relacionados a atividades econômicas organizadas em rede. De acordo com essa perspectiva teórica, os diferentes tipos de "poder" relacionados a atividades econômicas envolvidas em RPGs são os seguintes: i) o poder corporativo: exercido por atores econômicos (empresas), que é distribuído assimetricamente na $\stackrel{\infty}{\sim}$ estrutura da rede; ii) o poder institucional: deกิ sempenhado por uma variedade de atores não

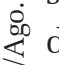
associações patronais, ONGs, associações diversas enraizadas localmente e que, de alguma forma, são envolvidos pelas atividades da RPG (Henderson et al., 2011).
RPG, é elementar para o processo de ampliação e captura do valor gerado na rede, em suas diferentes escalas (locais, nacionais, globais).

A abordagem das RPGs trata a noção de valor por três dimensões: criação, ampliação e captura. A criação de valor refere-se, prioritariamente, às atividades em que a firma (agente econômico) está envolvida, através do processo de trabalho (Santos, 2011, p. 133). A ampliação do valor relaciona-se a questões como o nível de transferência de tecnologia, a cooperação intrarrede (com fornecedores e subcontratadas), com o intuito de sofisticar os processos de trabalho, e o grau de autonomia de firmas locais para a criação de valor. A captura de valor diz respeito às circunstâncias em que o valor, gerado e ampliado em determinada localidade, será capturado para seu próprio beneficiamento. Nesse caso, questões de política governamental e de direitos de propriedade da firma são importantes, mas envolvem também ações coletivas de segmentos da sociedade civil, que reivindicam maior incorporação do valor criado localmente (Henderson et al., 2011; Santos, 2011)

Essa percepção multidimensional da atividade econômica é importante quando se observa que políticas de desenvolvimento com setores econômicos integrados à RPGs, ao mesmo tempo em que se propõem a ser vetores de indução de transformações socioeconômicas, em âmbito regional, dependem, para seu sucesso, de estratégias das diferentes empresas inseridas nessas redes (Ramalho, 2015).

$\mathrm{O}$ artigo tem por objetivo estudar as transformações recentes na siderurgia primária localizada na Amazônia, considerando os efeitos da crise econômica de 2008 e as diferentes estratégias dos atores envolvidos na RPG do ferro-gusa para enfrentar esses efeitos, dividindo-se em duas partes, além desta introdução e sua conclusão. Na primeira, é apresentada a dinâmica política e institucional operada a partir da década de 1970, no apoio à iniciativa de atividades produtivas na Amazônia Oriental. Na segunda parte, é utilizado um 
recorte temporal mais recente para analisar o mercado de produção e trabalho aqui destacado, compreendido entre 2006 (ano em que o ferro-gusa produzido na Amazônia Oriental passa ter maior relevância nacional, em termos de quantidade produzida e valor exportado) e 2013, destacando-se atuação do poder coletivo local nesse período.

\section{AMBIENTE INSTITUCIONAL E A FORMAÇÃO DO TERRITÓRIO PRODUTIVO DE AÇAILÂNDIA}

O município de Açailândia localiza-se na Microrregião Homogênea (MRH) de Imperatriz, contando com uma área territorial de $5.806,371 \mathrm{~km}^{2}$ e, em 2010, possuía uma população de 104.047 habitantes (IBGE, 2011). A constituição do município de Açailândia esteve relacionada aos projetos de infraestrutura que foram direcionados para a região a partir da década de 1960, como é o caso da rodovia Belém-Brasília (BR-010), que, fazendo parte da proposta de colonização da Amazônia pelo governo federal, impulsionou a chegada de migrantes de vários locais do país à região, muitos dos quais eram camponeses que passaram a cultivar arroz, milho, mandioca e feijão em Açailândia (Carneiro, 1995).

Esse quadro se modifica no decênio seguinte, com a política de incentivos à atividade agropecuária, os quais propiciam o surgimento de latifúndios - no processo de privatização da terra - e a consequente expulsão dos camponeses. No final da década de 1970, a construção da BR-222, ligando Açailândia à cidade de Santa Luzia, proporciona a povoação da parte oriental do município. Nesse mesmo período, Açailândia torna-se alvo da instalação de diversas indústrias madeireiras que - até a supressão quase total das florestas na localidade na década de 1990 - passam a ser um importante elemento da economia da região (Carneiro, 1994; Lima Filho; Masson; Costa, 2011). Com o Programa Grande Carajás (PGC), no final da década de 1970, Açailândia começa a ganhar os contornos de maior relevo da sua economia atual. O PGC esteve incluído no bojo do projeto governamental de modernização da região amazônica, tendo como escopo a exploração mineral na Amazônia Oriental, como no caso do minério de ferro extraído da Serra de Carajás no Pará, operado pela então Companhia Vale do Rio Doce - Vale S/A após uma etapa de estudos preliminares, feitos na década de 1970, que examinaram as possibilidades de exploração mineral. Estiveram relacionados com o PGC outros projetos de infraestrutura que possibilitaram a exploração mineral na Amazônia Oriental: a Estrada de Ferro Carajás (EFC), ligando a mina de Carajás a São Luís, com 890 km de extensão; o porto de Ponta da Madeira e a Hidrelétrica de Tucuruí, ambos componentes do Projeto Ferro Carajás (PFC).

Nas palavras de Carneiro, o

... governo federal tendo em vista a magnitude das obras de infraestrutura e o volume de recursos que seriam mobilizados, resolveu ampliar o PFC, criando um programa regional de desenvolvimento denominado Programa Grande Carajás, através do Decreto-Lei n. 1813 de 21 de novembro de 1980 (Carneiro, 2013, p. 44).

A expectativa do PGC era proporcionar uma diversificação crescente de atividades produtivas, gerar cerca de 44 mil empregos diretos, além de estimular a alteração no perfil de distribuição de renda na região (Monteiro, 2006).

A infraestrutura montada pelo PFC para viabilizar o transporte e a exportação mineral de Carajás configura-se, nesse contexto, como a principal fomentadora da instalação do Polo Siderúrgico de Carajás (PSC) no final da década de 1980. No momento do seu apogeu, no início do século XXI, o PSC chegou a possuir dezoito unidades industriais produzindo ferro-gusa (matéria-prima fundamental para a produção de aço), ${ }^{2}$ em grande parte para o

${ }^{2}$ Segundo Evangelista (2008, p.49), o "ferro-gusa é um produto resultado da fundição do minério de ferro com carvão e calcário num alto forno, contendo normalmente até 5\% e calcário num alto forno, contendo normalmente até $5 \%$
de carbono e demais elementos residuais como manganês, 
mercado externo. Nisso reside à importância do PFC e dos portos para a atividade produtiva das siderúrgicas. Essas unidades foram distribuídas em cinco municípios: Marabá e Barcarena, no Pará, e Bacabeira, Pindaré-Mirim e Açailândia, no Maranhão.

Para abastecer essa produção siderúrgica, que, no final de 2008, representava cerca de $40 \%$ do total produzido no Brasil, fez-se necessário o estabelecimento de uma ampla rede de fornecedores de carvão vegetal, geralmente oriundo de mata nativa, uma vez que ele é o principal insumo energético utilizado na siderurgia amazônica (Assis; Carneiro, 2015). Ou seja, essa expansão da siderurgia teve como um de seus principais efeitos o estímulo ao surgimento de uma atividade econômica até então inédita na região, promovendo o surgimento de uma vasta rede de produtores individuais de carvão vegetal, cuja característica central é a forte presença de formas precárias de trabalho.

A atividade laboral realizada nessas carvoarias enquadrava-se nas características do chamado trabalho escravo contemporâneo (Moura, 2006), variando entre situações de jornadas de trabalho exaustivas, trabalho insalubre e sem o devido uso de equipamentos de proteção individual (EPIs), condições de higiene e alojamento precárias, ou convergindo $\stackrel{\infty}{*}$ muitos desses traços numa mesma situação, N como mostram diferentes relatórios produzidos $\dot{8}$ por entidades de defesa de direitos humanos (Greenpeace, 2012; Lima Filho; Masson; Costa, 2011). Nos últimos anos, contudo, um processo de "desterceirização", com a incorporação pelas indústrias siderúrgicas da produção do carvão $\dot{s}$ vegetal (etapas de reflorestamento e carvoejamento), rompeu com a rede de produtores independentes que sustentava essa forma de trabalho degradante (Mancini, 2015).

De acordo com alguns estudos, apesar de possuir semelhanças com outros nichos de produção de ferro-gusa nacional, o que era produzido no âmbito do PSC distingue-se do restante do país por conta de três elementos: fósforo, enxofre e silício". a dependência do mercado externo para a existência da produção, a dependência quase exclusiva do minério de ferro fornecido pela Vale, e uma repercussão em decorrência dos problemas sociais e ambientais ocasionados pelo processo de produção na Amazônia (Carneiro, 2013).

Dentre as unidades siderúrgicas do PSC, cinco foram implantadas em Açailândia: Viena Siderúrgica (Grupo Valadares), Fergumar, Simasa e Cia. Vale do Pindaré (as duas últimas empresas do grupo Queiroz Galvão), além da Gusa Nordeste (grupo Ferroeste). Todas essas siderúrgicas são semi-integradas, ou seja, seus produtos não são acabados ou semiacabados de aço, mas somente o ferro-gusa, que posteriormente é vendido a siderúrgicas integradas - aquelas cujos produtos são semiacabados e acabados de aço (laminados).

Pesquisas recentes (Mancini, 2015; Ramalho; Carneiro, 2015) identificam dois processos de relevo na atividade atual da siderúrgica de Açailândia, os quais adicionam importantes modificações em seu mercado de trabalho: i) a desterceirização da produção de carvão vegetal para fins siderúrgicos, e o consequente desmonte da rede pulverizada de fornecimento que caracterizava o abastecimento desse insumo; ii) a verticalização da produção com a inauguração de uma aciaria integrada por parte do grupo Ferroeste, com a finalidade de agregar valor à produção de ferro-gusa e tornar o setor menos vulnerável ao mercado externo.

\section{PODER COLETIVO, CRÍTICA SO- CIAL E A RECONFIGURAÇÃO ECONÔMICA DO TERRITÓRIO PRODUTIVO DE AÇAILÂNDIA}

Desde a implantação do setor siderúrgico no final dos anos 1980, vem se conformando, no território produtivo de Açailândia, a partir de diferentes segmentos da sociedade civil, um poder coletivo (Henderson et al., 2011) que atua contra as desigualdades sociais verifi- 
cadas nesse local. Apesar de vago, esse escopo de atuação pode ser pormenorizado da seguinte forma: esse poder coletivo se orienta pelas externalidades e assimetrias sociais efetivamente engendradas - ou que se esperava efetivar - pelo modelo de desenvolvimento que foi posto em marcha sob o fomento do ambiente institucional orquestrado pelo PGC e PFC. Isso significa que as pautas reivindicatórias desse poder coletivo conformam uma crítica social (Boltanski; Chiapello, 2009) aos efeitos ocasionados - ou expectativas não realizadas - pelo polo siderúrgico, estruturado na forma de uma rede de produção global.

As diferentes pautas de reivindicação que coadunam esses diferentes atores coletivos estruturam-se em três grandes blocos:

- Combate à degradação ambiental e à poluição urbana. São externalidades da produção guseira que originam diversas manifestações por parte dos moradores do bairro do Pequiá de Baixo.

- Mobilização contra as condições de trabalho degradantes na atividade de produção de carvão vegetal. As ações de combate a esse tipo de situação, no território produtivo de Açailândia, vêm sendo desenvolvidas por entidades de direitos humanos (CDVDH e Justiça nos Trilhos).

- Crítica ao pequeno grau de articulação entre as atividades estimuladas pelas políticas públicas (PGC e PFC) e a economia local.

O quadro abaixo apresenta os principais atores envolvidos na situação de crise e as modalidades de poder a que se referem:

\begin{tabular}{|c|c|c|}
\hline Corporativo & Coletivo & Institucional \\
\hline 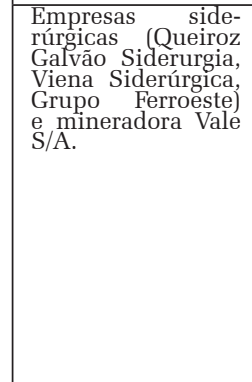 & $\begin{array}{l}\text { Movimentos popu- } \\
\text { lares (Associaçao de } \\
\text { Moradores do Bairro } \\
\text { de Pequiá), movimen- } \\
\text { tos de direitos huma- } \\
\text { nos (Centro de Defesa } \\
\text { da Vida e dos Direitos } \\
\text { Humanos, CDVDH, } \\
\text { Campanha Justiça } \\
\text { nos Trilhos), segmen- } \\
\text { tos religiosos (Igreja } \\
\text { Católica) e movimen- } \\
\text { tos sindicais urbanos } \\
\text { urbanos (em especial, } \\
\text { o Sindicato dos Tra- } \\
\text { balhadores Metalúr- } \\
\text { gicos de Açailândia } \\
\text { - STIMA). }\end{array}$ & $\begin{array}{l}\text { Agências esta- } \\
\text { tais e atores po- } \\
\text { líticos: Assem- } \\
\text { bleia Legisla- } \\
\text { tiva do Estado } \\
\text { do Maranhão } \\
\text { (ALEMA) e Se- } \\
\text { nado Federal. }\end{array}$ \\
\hline
\end{tabular}

Os eventos socioeconômicos desencadeados a partir dos acontecimentos da crise global de 2008 propiciaram uma ação coletiva que conjugou esses atores e unificou as suas pautas reivindicatórias (Ramalho; Carneiro, 2013). Essa unificação de pautas reivindicatórias, eixos axiais das externalidades da produção industrial desse território, foi possibilitada pelo contexto de proximidade presente no território, na medida em tal contexto colocou, em copresença, atores coletivos que constituíram uma densidade territorial através de interações continuadas, dando origem a "externalidades cognitivas" (aprendizagens) (Reis, 2005) sobre um ponto comum: o "modelo de desenvolvimento" materializado pelo setor industrial e sua cadeia produtiva. Esses elementos da dinâmica territorial - proximidade e densidade - vieram à tona num momento em que o setor industrial de Açailândia sofria impactos decorrentes da crise da RPG do aço, a qual se insere a jusante.

É interessante observar a atuação desse poder coletivo, na medida em que a implantação do polo industrial em Açailândia - apesar de concebida primeiramente como veículo de desenvolvimento regional e diminuição de desigualdades entre as regiões do país - esteve bem mais vinculada com a eficácia da acumulação e desempenho da racionalidade econômica ${ }^{3}$ propriamente dita por parte do poder corporativo do que com demandas locais e (ou) efeitos dessa atividade na economia local. Houve, portanto, uma interpelação de atores não econômicos (poder coletivo) confirmando contingências territoriais que atuam como elementos de incerteza na racionalidade desempenhada por atores econômicos.

\section{O poder coletivo face à crise econômica $e$ à recuperação da capacidade produtiva na indústria siderúrgica}

A crise econômica mundial desenca-

${ }^{3}$ No sentido do homo economicus da economia clássica e neoclássica, aquele que persegue os ganhos econômicos, maximizando os resultados de sua ação em coerência com os meios (escassos) empregados (Steiner, 2006). 
deada em 2008, nos Estados Unidos, ${ }^{4}$ trouxe nítidos efeitos na estrutura ocupacional e no mercado de trabalho do território produtivo de Açailândia, no que tange à quantidade e distribuição de ocupados na atividade produtiva diretamente relacionada às demandas provenientes daquele país - indústria siderúrgica -, bem como às atividades ligadas à sua cadeia de produção (carvoejamento), incluindo as que são terceirizadas: reflorestamento, montagem e manutenção de altos-fornos, transporte e descarregamento de carvão vegetal.

O início das demissões em massa e a redução da capacidade produtiva do polo siderúrgico de Açailândia começou logo no segundo semestre de 2008. Apesar de esse ter sido o ano em que a crise global emerge, impactando diretamente o mercado de aço norte-americano, principal comprador do ferro-gusa produzido em Açailândia, o gráfico a seguir demonstra que, em 2008, o valor da tonelada exportada atinge sua maior cotação no mercado mundial (com uma arrecadação de US\$ 483.917.087, e o preço da tonelada, na média, de US\$486,00), o que nos leva a crer que as siderúrgicas do polo de Açailândia conseguiram manter sua margem de lucro nesse período (Gráfico 1).

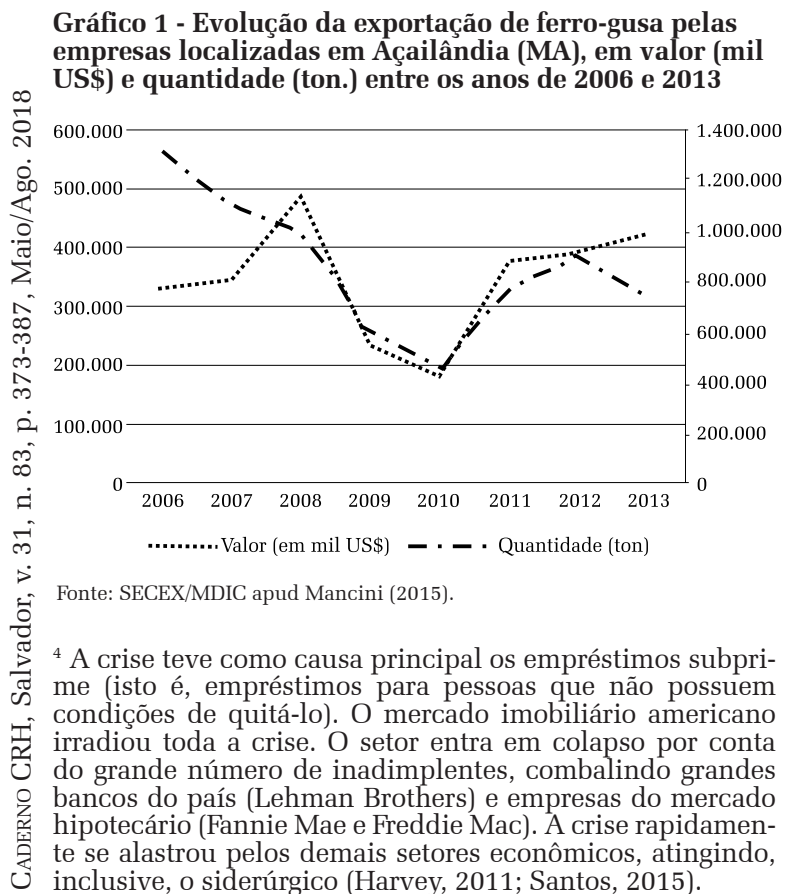

Gráfico 1 - Evolução da exportação de ferro-gusa pelas empresas localizadas em Açailândia (MA), em valor (mil
A diminuição nos contratos de venda causou uma ociosidade na capacidade produtiva das empresas guseiras, fazendo-as operar com $50 \%$ da capacidade - além de três, das cinco, que, a princípio, fecharam as portas - e exportando o ferro-gusa estocado até o primeiro trimestre de 2009. Segundo Carneiro e Ramalho (2009), nesse ínterim, que vai dos meados de 2008 ao primeiro trimestre de 2009, as siderúrgicas, além de terem continuado a exportar, tiveram possibilidade de retardar as demissões, mas

... continuaram exportando e lucrando com a ven-
da do ferro-gusa estocado, mas de forma oportunis-
ta aproveitaram o cenário da crise econômica para
demitir trabalhadores. Os dados comprovam que as
demissões poderiam ter sido retardadas enquanto
se confirmavam reduções nas exportações de ferro
gusa. (Carneiro; Ramalho, 2009, p.43).

Os efeitos da retração das atividades do setor siderúrgico na estrutura ocupacional são percebidos a partir de 2008. Os setores econômicos que absorveram as consequências da crise, mediante demissões, foram os da indústria e da agropecuária e extração florestal, esse último por conta das atividades que envolvem a cadeia de produção do ferro-gusa, como o carvoejamento e reflorestamento. O gráfico 2 mostra a evolução do saldo ${ }^{5}$ por setor de atividade econômica e o saldo geral do município de Açailândia entre os anos de 2006-2013.

Nos anos de 2006 e 2007, o saldo do setor da indústria ${ }^{6}$ foi positivo. Não aparece no gráfico, mas, em 2006, esse setor admitiu 2.407 e demitiu 2.405 pessoas, ficando com um positivo (+2). Em 2007, admitiu 2.902 e demitiu 2.717 pessoas, contando com um saldo de

${ }^{5} \mathrm{O}$ saldo é resultado da diferença entre o total de admitidos e demitidos - se houve mais admitidos do que demitidos, o saldo é positivo, se houve mais demitidos é negativo. O mesmo vale para o saldo geral, que mede o saldo de cada setor de atividade econômica por ano.

${ }^{6} \mathrm{O}$ emprego industrial refere-se aqui, sobretudo, aos empregos relacionados aos subsetores da Indústria Metalúrgica e Mecânica (diretamente relacionados à siderurgia). Conforme dados da Relação Anual de Informações Sociais (RAIS) para 2015/2016, outros subsetores da indústria presentes na região, como a indústria de produtos alimentícios e bebidas, madeira e mobiliário e indústria têxtil, obtiveram relevância bem abaixo da atividade metalúrgica quanto ao número de empregos gerados. 


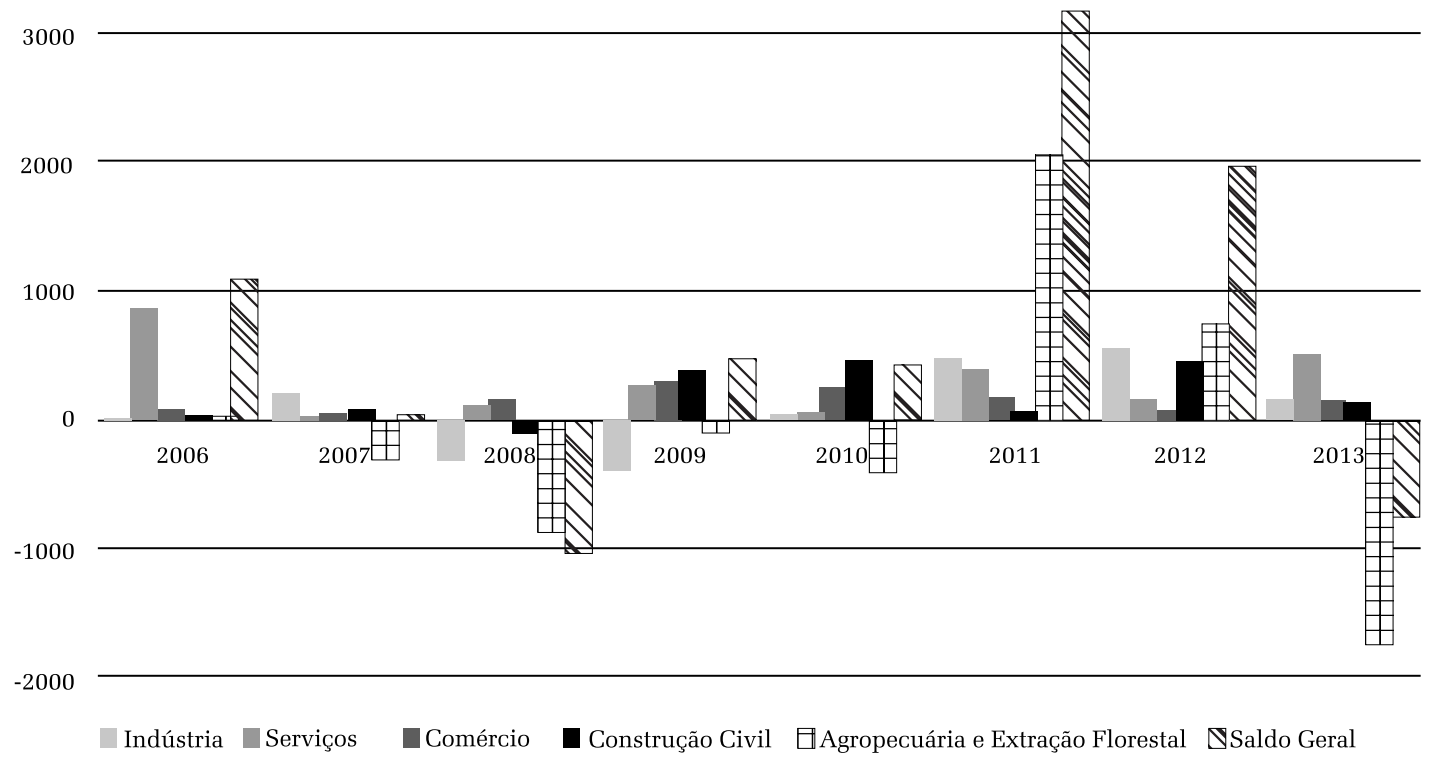

Fonte: CAGED apud Mancini (2015).

+185. O ano de 2008, porém, apresenta um cado de trabalho local, seu foco em produzir alto contraste com os anos anteriores, quando somente para exportar o coloca numa posição contabiliza um saldo de -312 (admitiu 1.082 de grande vulnerabilidade às oscilações da pessoas e demitiu 1.394). É possível perceber economia mundial. O gráfico 3 apresenta duas a forte presença do setor da indústria na es- variáveis com curvas muito semelhantes: evotrutura ocupacional de Açailândia na medida lução das exportações de ferro gusa e evolução em que o saldo geral do município vai de um do emprego formal no setor da indústria entre positivo de 1.031 em 2006, passando para 779 os anos de 2006 e 2013.

em 2007 e despencando para -659 em 2008, ano com o pior saldo para o setor da indústria, levando consigo o setor da agropecuária e da extração florestal (que fechou 2008 com um saldo negativo de -872), por conta das atividades de carvoejamento e reflorestamento. $\mathrm{O}$ saldo geral volta a subir em 2009 (+745), embora os setores da indústria e da agropecuária e extração florestal tenham continuado a demitir (-396 e -85, respectivamente), por conta de outros setores (comércio e serviços) que se mantiveram mais estáveis no período de crise.

Mesmo que o setor da indústria prevaleça ao longo da trajetória do território produtivo de Açailândia, ao lado do setor de serviços e o comércio, no que diz respeito à proporção de pessoal ocupado, o que demonstra a sua importância no âmbito da economia e do mer-

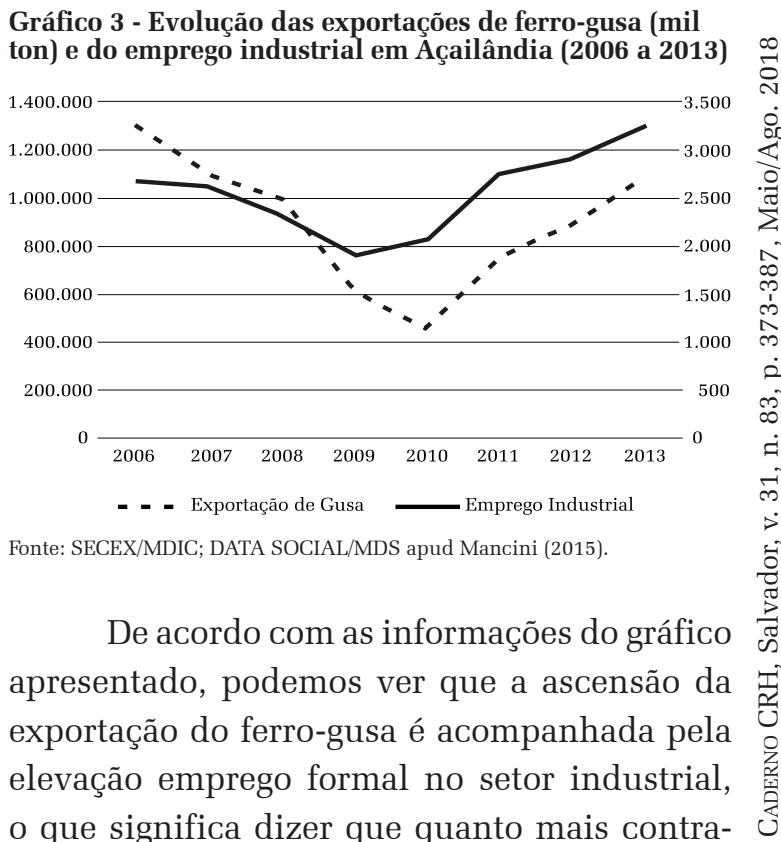


tos forem firmados (no mercado externo) para a exportação guseira, maior o crescimento e a estabilidade dos empregos no setor. De forma inversa, a escassez dos contratos para venda do ferro-gusa, como foi observado a partir do segundo semestre de 2008, representou um dos sinais do início da debilidade das indústrias e do emprego no setor (Carneiro, 2008).

O quadro 2 apresenta a situação do funcionamento das siderúrgicas de Açailândia antes e depois da crise de 2008. Em 2008, as cinco siderúrgicas estavam em estado ativo, com o valor arrecadado em exportações de ferro-gusa na faixa dos milhões de dólares (Carneiro, 2008) por cada uma. A partir de 2009, três siderúrgicas inicialmente foram desativadas (Fergumar, Simasa e Cia. Vale do Pindaré), permanecendo, até o final de 2016, somente a primeira fechada.

Quadro 2 - Situação do funcionamento das indústrias siderúrgicas de Açailândia nos períodos pré e pós crise de 2008

\begin{tabular}{|l|c|c|c|}
\hline \multicolumn{1}{|c|}{ Empresa } & Pré-crise & Pós-crise & $\begin{array}{c}\text { Número de } \\
\text { altos-fornos }\end{array}$ \\
\hline $\begin{array}{l}\text { Viena Siderúrgica do } \\
\text { Maranhão S/A }\end{array}$ & Ativa & Ativa & 5 \\
\hline $\begin{array}{l}\text { Queiroz Galvão } \\
\text { Siderurgia }\end{array}$ & Ativa & Ativa & 5 \\
\hline Gusa Nordeste S/A & Ativa & Ativa & 3 \\
\hline $\begin{array}{l}\text { Ferro Gusa do } \\
\text { Maranhão Ltda. }\end{array}$ & Ativa & Desativada & 2 \\
\hline
\end{tabular}

Fonte: Mancini (2015)

Se, num primeiro momento, a estag-

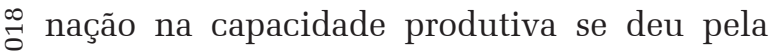
$\stackrel{\sim}{\circ}$ ausência de contratos, a característica (e vul$\sum_{1}^{\infty}$ nerabilidade) da indústria siderúrgica de Açailândia de dependência do mercado norte-americano ${ }^{7}$ tornou-se patente na voz de atores coletivos locais. A não concretização das expectativas vislumbradas pelo PGC para a região - diversificação de atividades produtivas $\dot{\text { e }}$ e verticalização - coadunou diferentes setores iे da sociedade civil de Açailândia, através da criação, sob liderança da Igreja Católica local,

${ }^{7}$ Mesmo no pós-crise, a dependência do mercado externo, - do mercado norte-americano em especial, ainda pauta o

destino do ferro-gusa produzido em Açailândia, como se

observa nas palavras de Sandro Raposo, engenheiro da

Gusa Nordeste: “... basicamente hoje [... exportamos para os] Estados Unidos, e um cliente que é a Nucor [Corporation]. Nós exportamos basicamente ferro-gusa pra eles" త $(20 / 01 / 2015)$. do "Movimento Popular em Favor da Justiça e da Dignidade Humana" em 2009:

\begin{abstract}
... em Açailândia, em tempos de crise e desemprego, uma aliança entre movimentos sociais permitiu a criação do "Movimento Popular em favor da Justiça e da Dignidade Humana". Trata-se de uma rede de entidades, associações de moradores, sindicatos, comunidades cristãs em busca e encaminhamentos locais para minimizar o impacto da crise e buscar alternativas e enriquecimentos para o modelo produtivo de Açailândia, marcado pela fragilidade e pouca diversificação. Esse movimento organizou em maio de 2009 um grande seminário sobre crise e desemprego. (Bossi, 2010, p.12).
\end{abstract}

Esse movimento organizou uma audiência em Açailândia, que trouxe à baila a debilidade não apenas momentânea pela qual passava a indústria siderúrgica local (demissões, perdas de direitos trabalhistas, como redução de salário, adicional noturno, hora extra, cesta básica, etc.), mas sua fragilidade crônica "de grande dependência de um produto de exportação (ferro-gusa) fortemente suscetível às oscilações da economia global" (Ramalho; Carneiro, 2013).

A crítica lançada ao modelo de desenvolvimento estabelecido em Açailândia baseia-se em alguns aspectos, como o valor agregado ao Produto Interno Bruto (PIB) proporcionado pelo setor da indústria e o conjunto massivo de incentivos e de infraestrutura pública que foram mobilizados para a instalação do polo industrial. A fragilidade econômica do município, por conta desse modelo de desenvolvimento baseado numa forma de acumulação dependente das demandas do mercado externo, logrou a contestação do poder coletivo local, que, mesmo décadas depois do lançamento do PGC, utilizou as metas ali vislumbradas como parâmetro para avaliar (e contestar) a incorporação das atividades siderúrgicas na economia e na sociedade local.

Nesse aspecto, a ação do poder coletivo frente à estrutura econômica (poder corporativo) e suas aspirações e percepções valorativas de tal estrutura atuam como uma "racionali- 
dade substantiva" que conflita com uma "racionalidade formal" (Swedberg, 2005). Essas distinções de racionalidade são weberianas, cunhadas em Economia e Sociedade. Enquanto a racionalidade formal é o arquétipo de racionalidade econômica, pautada na congruência entre meios e fins num contexto em que os meios são escassos, a racionalidade substantiva (ou formas não econômicas de ação racional) é conduzida por valores e leva em conta se “"o abastecimento de [...] grupos de pessoas' está de acordo com certos valores absolutos, sejam eles de natureza política, ética, filosófica..." (Swedberg, 2005, p.63). O conflito entre esses dois tipos de racionalidade, na economia, é garantido pela "desigualdade na distribuição de renda” (Swedberg, 2005, p. 65).

É interessante destacar que esses documentos vieram a público num contexto de crise da indústria siderúrgica, em que as pautas reivindicatórias de diferentes segmentos da sociedade civil relacionadas aos efeitos da produção guseira foram unificadas, tendo como protagonista o Sindicato dos Trabalhadores Metalúrgicos de Açailândia (STIMA), que ampliou seu repertório de mobilização (antes mais tradicional, pautado em greves gerais e paralisação de fábrica), através de audiências públicas realizadas em âmbito municipal e estadual (Ramalho; Carneiro, 2013).

A oportunidade para a formação dessa coalizão de atores coletivos foi o superfaturamento do preço do minério de ferro realizado pela Vale S/A em 2010. Em outubro de 2009, com a diretoria reformulada, com membros vinculados à principal sindical brasileira (Central Única dos Trabalhadores, CUT), depois de substituir uma gestão de 18 anos, o STIMA passa por uma campanha de recuperação financeira e de filiação. Em 2009, no ápice do desemprego industrial em Açailândia, o STIMA contava com 98 sócios. Com baixa credibilidade na sua base sindical, a nova diretoria passa a ser mais atuante entre os trabalhadores de sua base (por meio de panfletagem na porta de fábrica, prestação de contas do sindicato, busca de benefícios creditícios, politização, etc.). Em 2015, o sindicato contava com cerca de 1.300 associados, dentro de uma base que girava em torno de 2.500 a 3.000 trabalhadores. A posse da nova diretoria se deu num momento em que o polo siderúrgico de Açailândia produzia com pouco mais de $50 \%$ da sua capacidade produtiva e com três indústrias que efetivamente chegaram a fechar as portas: Cia. Vale do Pindaré e Siderúrgica do Maranhão (Simasa) (do Grupo Queiroz Galvão) e Ferro Gusa do Maranhão (Fergumar).

Em março de 2010, a Vale S/A, que fornece com quase exclusividade o minério de ferro para o PSC, elevou o preço do insumo, que passou de US $\$ 48,00$ para US $\$ 137,00$, a tonelada. Não por acaso, 2010 foi o ano com a menor quantidade de ferro-gusa exportada pelo polo siderúrgico de Açailândia (456.274 mil/ton). Essa ocorrência levou a uma aproximação entre o sindicato patronal (SIFEMA) e o dos trabalhadores (STIMA). Na ocasião, o sindicato dos trabalhadores aderiu às críticas realizadas anteriormente contra a Vale S/A por movimentos sociais locais. Essas três partes, sindicato dos trabalhadores, sindicato patronal e demais segmentos da sociedade civil, realizaram uma ação conjunta contra a Vale S/A.

A coalizão com as pautas reivindicatórias de outros atores coletivos foi possibilitada pelo fato de a Vale S/A estar na posição de principal indutor do desenvolvimento industrial na região, desde sua época de empresa estatal. Nesse sentido, essa empresa é considerada a principal responsável pela implantação dos polos siderúrgicos na Amazônia oriental, na medida em que geria a estrada de ferro que possibilitava a exportação do ferro-gusa. Essa posição fez da Vale S/A "o foco central da crítica dos diferentes movimentos sociais (camponês, direitos humanos, sindical, etc.) e dos questionamentos quanto ao modelo de desenvolvimento vigente na região" (Ramalho; Carneiro, 2013, p. 16). É nesse contexto que o STIMA amplia seu repertório de ação e mobilização (Tarrow, 2009) por meio de audiências públicas, nas quais passa a 
expor a situação econômica de Açailândia, em especial do setor da indústria.

Foram três audiências realizadas, que consistiram em esforços de intermediação por parte de políticos (deputados estaduais), com a finalidade de arrefecer a crise no setor siderúrgico através de mobilizações voltadas para a tentativa de diminuição do preço do minério de ferro fornecido pela Vale S/A.

Quadro 3 - Cronograma de audiências entre atores do poder coletivo, institucional e corporativo

\begin{tabular}{|l|c|c|c|}
\hline $\begin{array}{c}\text { Audiência } \\
\text { pública }\end{array}$ & Local & Objetivo & $\begin{array}{c}\text { Principais } \\
\text { atores }\end{array}$ \\
\hline $\begin{array}{l}\text { Julho de } \\
2010\end{array}$ & $\begin{array}{c}\text { Senado } \\
\text { Federal }\end{array}$ & $\begin{array}{c}\text { Discutir a crise e } \\
\text { suas possibilidades } \\
\text { de reversão no } \\
\text { setor industrial de } \\
\text { Açailândia. }\end{array}$ & $\begin{array}{c}\text { Sindicato dos } \\
\text { metalúrgicos } \\
\text { e atores } \\
\text { políticos. }\end{array}$ \\
\hline $\begin{array}{l}\text { Agosto de } \\
2010\end{array}$ & ALEMA & $\begin{array}{c}\text { Discutir a crise } \\
\text { e modelo de } \\
\text { desenvolvimento } \\
\text { posto em marcha em } \\
\text { Açailândia desde a } \\
\text { década de 1980. }\end{array}$ & $\begin{array}{c}\text { Sindicato dos } \\
\text { trabalhadores, } \\
\text { movimentos } \\
\text { sociais e atores } \\
\text { políticos. }\end{array}$ \\
\hline $\begin{array}{l}\text { Novembro } \\
\text { de } 2010\end{array}$ & ALEMA & $\begin{array}{c}\text { Negociar o preço } \\
\text { do minério de ferro } \\
\text { e reverter o quadro } \\
\text { de demissóes dos } \\
\text { metalúrgicos em } \\
\text { Açailândia }\end{array}$ & $\begin{array}{c}\text { Sindicato dos } \\
\text { trabalhadores, } \\
\text { atores } \\
\text { políticos e } \\
\text { empresários. }\end{array}$ \\
\hline
\end{tabular}

No dia 12 de julho de 2010, o STIMA realizou uma reunião com o então presidente do Senado e ex-presidente da República, José Sarney, que se comprometeu com a situação apresentada pelos metalúrgicos: crise na indús-

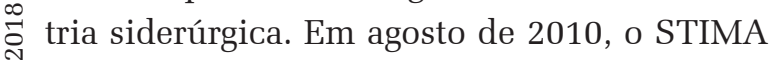
$\dot{\circ}$ apropriou-se do movimento "Assim não Vale", L lançado pelo movimento de direitos humanos "Justiça nos Trilhos", em audiência realizada na Assembleia Legislativa do Estado do Marain tivos que apoiavam o movimento estiveram na $\infty$ audiência, em conjunto com os sindicalistas; द. no dia 23 de novembro de 2010, foi realizada outra audiência pública na ALEMA, para trao tar das demissões dos trabalhadores do setor industrial de Açailândia. Nessa última audiência, foi anunciado pelo presidente do STIMA que a pressão sobre a Vale S/A tinha surtido efeito, e que ela iria reduzir o preço do minério de ferro de US\$ 137, 00 para US\$ 93, 00.
A diminuição no preço do minério de ferro permitiu um crescimento nas exportações do ferro-gusa a partir de 2011, dando um salto de $456.274 \mathrm{mil} /$ ton em 2010 para 757. 991 mil/ton no ano seguinte, assim como uma recuperação no emprego industrial (que passou de 2.079 no ano de 2010 para 2.749 em 2011), permitindo ainda o retorno das atividades da Queiroz Galvão Siderurgia, que havia fechado as portas - sem, entretanto, possibilitar a reabertura da Fergumar, ainda hoje fechada.

Nesse movimento de recuperação das exportações e de luta pela diminuição do preço do minério de ferro fornecido pela Vale S/A, foi firmada uma parceria entre o sindicato patronal e o dos trabalhadores, que se utilizaram da distribuição assimétrica de poder na RPG, em que as "firmas menores, às vezes (e por motivos contingentes), têm autonomia suficiente para desenvolver e exercitar suas próprias estratégias para aperfeiçoar suas operações" (Henderson et al., 2011, p. 157). Nessa parceria, o sindicato patronal atuou com o sindicato dos trabalhadores da seguinte forma: i) no apoio à mobilização e no incentivo das ações levadas a cabo pelo STIMA e demais atores coletivos, pois o seu envolvimento público com a situação era comprometedor, na medida em que corria o risco de receber restrições comerciais por parte da Vale S/A, ou, como nas palavras presidente do STIMA: "não podia aparecer por medo de repressão da própria Vale” (Entrevista realizada em 12/05/2014); e ii) no apoio financeiro às ações do sindicato dos trabalhadores.

Apesar da cooperação, após a redução do preço do minério de ferro e retomada das exportações de ferro-gusa num melhor nível, as siderúrgicas não atenderam, de pronto, as reivindicações trabalhistas que vinham sendo pautadas pelo STIMA. A solução encontrada foi investir num repertório de mobilização mais tradicional do sindicato, por intermédio da realização de uma greve em fevereiro de 2011.

A greve do dia 14 de fevereiro de 2011 começou de forma típica, com o fechamento dos portões da fábrica de maior capacidade 
produtiva do polo industrial de Açailândia Viena Siderúrgica -, e contou com a presença decisiva dos moradores do Pequiá de Baixo, que, na ocasião, reivindicavam seu remanejamento ${ }^{8}$ para outro loteamento, por conta da intensa poluição urbana e da disposição indevida de refugos da produção siderúrgica no local - o que, por anos, ocasionou problemas de saúde nos moradores do bairro (Evangelista, 2008; FIDH, 2011). Após obter sucesso em suas reivindicações, no dia 15 de fevereiro de 2011, o STIMA só findou a greve sob a condição de o SIFEMA também atender as reivindicações dos moradores do Pequiá de Baixo.

Após as audiências públicas capitaneadas pelo STIMA, mas incorporando as representações e as pautas reivindicatórias de outros atores coletivos (locais) acerca do modelo de desenvolvimento posto em marcha em Açailândia, houve uma recuperação no nível das exportações do ferro-gusa, e os trabalhadores que protagonizaram a greve - inicialmente demitidos - foram readmitidos em seus postos de trabalho (recuperação do emprego industrial), bem como foram retomados os direitos trabalhistas, a princípio perdidos com a eclosão da crise global em 2008-2009.

O grau de importância da ação do poder coletivo frente à crise sofrida pela indústria siderúrgica em Açailândia pode ser devidamente aferido se analisado no contexto de todo o Polo Siderúrgico Carajás (PSC). As onze siderúrgicas localizadas no município de Marabá (PA), por exemplo, não obtiveram o mesmo poder de reação frente à crise global. Fortemente combalidas pela crise no mercado norte-americano e a consequente queda no preço do ferro-gusa, pois $90 \%$ da produção das siderúrgicas paraenses destinavam-se a esse mercado (Santos, 2015) -, iniciou-se um processo demissionário e logo cinco siderúrgicas interromperam suas atividades até o final de 2008. O motivo princi-

${ }^{8}$ Existe uma luta levantada há anos pelos moradores do Pequiá - em conjunto com segmentos da sociedade civil para o reassentamento da comunidade em uma área fora da influência dos resíduos poluentes, sobretudo gasosos, e dos ruídos provocados pelo processo de produção do ferro-gusa (Evangelista, 2008; FIDH, 2011). pal seria a constância do alto preço do minério de ferro cobrado pela Vale S/A às siderúrgicas paraenses, o que ainda tornava a produção e a exportação de ferro-gusa inviável, mesmo com o reaquecimento do mercado externo e a recuperação das exportações desse produto a partir de 2011. No final de 2013, somente quatro usinas, das onze que chegaram a funcionar em Marabá, estavam em atividade, o que explica a queda contínua das exportações desse município, ao contrário do observado em Açailândia (Gráfico 4).

Gráfico 4 - Exportações de ferro-gusa (em ton.) do Polo Siderúrgico de Carajás e das empresas localizadas em Açailândia/MA e Marabá/PA

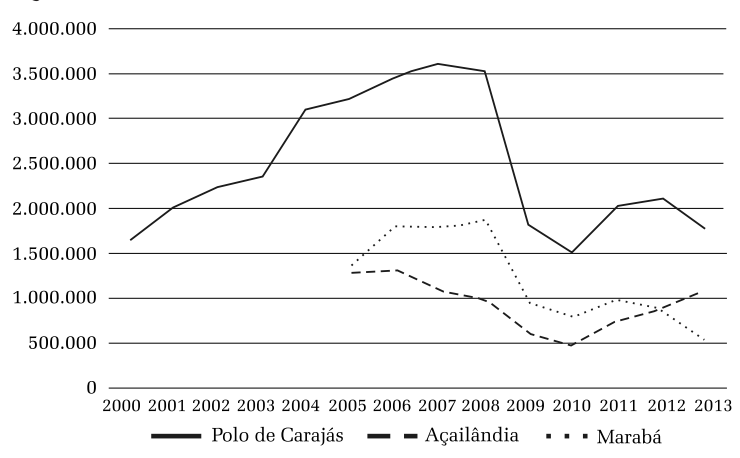

Fonte: SECEX/MDIC apud Ramalho e Carneiro (2015)

A ação do poder coletivo e os devidos efeitos no processo de recuperação da indústria siderúrgica parecem apontar para o enraizamento territorial (Henderson et al., 2011) que essa atividade possui em Açailândia, mas não em Marabá. A possibilidade de as empresas absorverem e serem constrangidas por dinâmicas sociais próprias às localidades (Id.,) demonstrou ser um importante aspecto na reestruturação econômica de Açailândia nos últimos anos.

Em Açailândia, a dinâmica de proximidade e a densidade (Reis, 2005) ${ }^{9}$ entre diferentes atores coletivos permitiu o compartilhamento de representações sobre o desenvolvimento local e sobre as externalidades 9 Densidade e proximidade referem-se à abordagem de territórios como matrizes relacionais. A proximidade consiste em "pessoas em copresença, são ordens relacionais; são consolidações de culturas práticas e de instituições; é conhecimento e é identidade partilhada de forma coletiva.” (Reis, 2005, p. 61); a densidade é desencadeada pela perduração do contexto de proximidade entre agentes atuantes num dado território. 
causadas pela produção industrial. O poder coletivo, diante das fragilidades econômicas da RPG, não somente sofreu com os impactos, mas, através de mobilizações e articulações próprias, possibilitou um efeito de retorno (feedback) sobre a rede, revertendo parte dos impactos e das medidas inicialmente tomadas sob o prisma da eficiência econômica (demissões e redução de direitos trabalhistas) pelo poder corporativo.

O resultado dessa mobilização não foi, entretanto, suficiente para reverter mais a fundo a situação econômica, na medida em que constituem territorializações que podem modificar o curso das ações desenvolvidas localmente pelo poder corporativo numa RPG, mas não podem escapar da dinâmica geral assente na rede (Henderson et al., 2011). Isso se reflete no fato de o polo siderúrgico de Açailândia ainda estar funcionando com sua capacidade parcial e não ter retomado o nível de produtividade, exportação e valor arrecadado do período pré-crise.

O emprego industrial em Açailândia esteve, por muito tempo, relacionado à baixa qualificação profissional e ao excessivo desgaste físico do trabalhador (Evangelista, 2008). Essas eram as características da mão de obra que participava diretamente do processo de

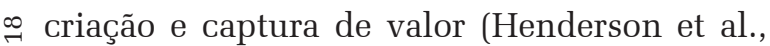
2011) realizado pelas siderúrgicas em Açailândia, que se somavam às condições de trabalho encontradas na cadeia de produção siderúrgica (atividades de carvoejamento), caracterizando um "padrão de acumulação amazônico" (Santos, 2011). É nesse aspecto que as ações $\dot{2}$ do poder coletivo incidem na questão da possibilidade de maior captura desse valor em âmbito local. As ações empreendidas pelo poder coletivo em prol do aumento de salários e dos direitos trabalhistas, ou mesmo quando direcionadas à possibilidade de ampliação ou manutenção dos postos de trabalho - nesse último caso, quando contribuíram para arrefecer os danos da crise no polo siderúrgico -, são exemplos de como uma maior participação na captura do valor criado pelas guseiras são reivindicados localmente. ${ }^{10}$

\section{CONSIDERAÇÕES FINAIS}

A maneira como os atores locais incorporaram o processo de estruturação destacado passa a ser determinante a partir dos anos de 1990. A conformação de uma crítica social (de cunho ambiental e trabalhista) lançada sobre as externalidades das atividades desempenhadas pela Vale S/A e pelo polo siderúrgico foi a forma pela qual, gradualmente, esses atores locais começaram a participar do processo de estruturação econômica de Açailândia. A formação de representações que atribuem a responsabilidade das siderúrgicas às externalidades ambientais, sociais e trabalhistas, foi um processo fundamental para a efetivação dos atores locais nesta estruturação.

As modificações em aspectos estruturais, tais como no processo produtivo e, por conseguinte, nas relações e mercado de trabalho, são o resultado dessa efetivação. Algumas dessas mudanças, muito impulsionadas pelo trabalho social operado pelo poder coletivo, talvez não fossem materializadas caso dependessem do viés da eficiência econômica. Como é constatado em escritos de atores locais, não se trata de querer a supressão das atividades que ali se estabeleceram, mas sim de torná-las mais favoráveis à sociedade e à economia de Açailândia: mais postos de trabalho, melhores condições de trabalho, quer dizer, mais próximas aos trâmites da CLT, e o consequente arrefecimento das externalidades que produzem há anos.

É nesse sentido que, embora os programas de desenvolvimento lançados ao território

${ }^{10} \mathrm{Na}$ análise de Fligstein (2001), a captura de valor estaria mais relacionada com os "Direitos de propriedade" da empresa. Para esse autor, direitos de propriedade constituem uma instituição de mercado que consiste em "relações sociais que definem quem pode reivindicar os lucros das empresas" (Fligstein, 2001, p. 29). O processo de reivindicação das "fatias" do lucro da empresa, realizada por acionistas, trabalhadores, partidos políticos, comunidades locais etc., relacionar-se-ia a "um processo político contínuo e contestável, e não ao resultado de um processo eficiente" (Fligstein, 2001, p. 29). 
em questão não tenham atingido exatamente as metas que previam, eles cumprem o papel fundamental (independentemente de aspectos valorativos) de todo o processo de desenvolvimento: provocar mudanças, sejam elas econômicas, sociais ou ambas. De uma forma ou de outra, o Projeto Ferro Carajás e o Programa Grande Carajás protagonizaram o processo de estruturação do território de Açailândia para aquém (ou mesmo, para além) de suas expectativas, mas não deixaram de produzir resultados econômicos e sociais concretos. Tais resultados, envolvidos com as representações dos atores locais de Açailândia, estão num ininterrupto processo de adaptação e reconfiguração.

Recebido para publicação em 05 de julho 2017 Recebido em 25 de maio de 2018

\section{REFERÊNCIAS}

ASSIS, W. S.; CARNEIRO, M.S. O uso do carvão vegetal como fonte de energia para o parque siderúrgico de Carajás: controvérsias ambientais, sociais e econômicas. In: CARNEIRO, M.S.; RAMALHO, J.R. (Orgs.) Ações coletivas em complexos minero-metalúrgicos: experiências na Amazônia e no Sudeste brasileiro. São Luís: EDUFMA, 2015.

BOLTANSKI, L.; CHIAPELLO, E. O novo espírito do capitalismo. São Paulo: Martins Fontes, 2009.

BOSSI, D. Impactos e resistências em Açailândia, profundo interior do Maranhão. In: FORUM Carajás. Mineração na Amazônia: estado, empresas e movimentos sociais. São Luís: Forum Carajás, 2010. p.22-32.

CARNEIRO, M. S Mercado e contestação: a atuação da crítica social e as transformações nas estratégias das empresas siderúrgicas de Carajás (1988-2012). Política e Sociedade, Florianópolis, v. 15, p. 282-313, 2016.

Crítica social e responsabilização empresarial: análise das estratégias para legitimaçã̃o da produção siderúrgica na Amazônia Oriental. Caderno $C R H$, Salvador, v. 21, n. 53. 323-336, 2008.

Estado e empreendimentos guseiros no programa grande Carajás: as políticas publicas a serviço da industrialização. In: CASTRO, E. M. R. de (Org). Amazônia em tempo de transição. Belém: Upa/NAEA, 1989.

latifundiária latifúndio agropecuário à empresa M.C.N.; COTA, R. G. (Org.) Dez anos da Estrada de Ferro Carajás. Belém: UFPA/NAEA, 1997. p. 223-250.

Terra, trabalho e poder: conflitos e lutas sociais no Maranhão contemporâneo. São Paulo: Annablume, 2013.

O Programa Grande Carajás e a dinâmica política na área de influência da ferrovia: políticas públicas e poder local na Amazônia. In: CASTRO, E.; MOURA, E. MAIA, M. L. Sá (Orgs.) Industrialização e grandes projetos: desorganização e reorganização do espaço. Belém: Gráfica e Editora da UFPA, 1995.
CARNEIRO, M. S; RAMALHO, J. R. A crise econômica mundial e seu impacto sobre o setor siderúrgico maranhense: relações entre o desempenho recente das empresas guseiras e o desemprego no município de Açailândia. In: CARNEIRO, M.D.S.; COSTA, W. C. (Orgs.) A terceira margem do rio: ensaios sobre a realidade do Maranhão no novo milênio. São Luís: EDUFMA, 2009. v. 1. p. 37-48.

CASTRO, E. Industrialização, Transformações Sociais e Mercado de Trabalho. In: CASTRO, E.M.R; MOURA, E.; MAIA, M. L. (Orgs.) Industrialização e grandes projetos desorganização e reorganização do espaço. Belém: Editora da UFPA, 1995. p. 91-120.

EVANGELISTA, L. N. A cidade da fumaça: a constituição do grupo operário do bairro do Pequiá no município de Açailândia/MA. 2008. 110 p. Dissertação (Mestrado em Ciências Sociais) - Programa de Pós-graduação em Ciências Sociais da Universidade Federal do Maranhão.

FEDERAÇÃO INTERNACIONAL DOS DIREITOS HUMANOS (FIDH). Brasil: quanto vale os direitos humanos? Os impactos sobre os direitos humanos relacionados à indústria da mineração e da siderurgia em Açailândia. 2011

FLIGSTEIN, N. Mercado como política: uma abordagem político-cultural das instituicões do mercado. Contemporaneidade e Educação, Rio de Janeiro, ano VI, n. 9, p. 26-55, 2001.

FLIGSTEIN, N; DAUTER, L. A sociologia dos mercados. Caderno CRH, Salvador, v. 25, n. 66, set./dez. 2012.

GREENPEACE. Carvoaria amazônica. Como a indústria de aço e ferro gusa está destruindo a floresta com a participação de governos. Manaus: Greenpeace, 2012. Disponível em: http://www.greenpeace.org/brasil/pt/Noticias/ Floresta-decarvao-e-violencia. Acesso em 10.06. 2012.

HARVEY, David. O enigma do capital e as crises do capitalismo. São Paulo: Boitempo, 2011.

HENDERSON, J. et al. Redes de produção globais e a análise do desenvolvimento econômico. Revista Pós Ciências Sociais, São Luís, n. 15, p.143-170, 2011.

INSTITUTO BRASILEIRO DE GEOGRAFIA E ESTATÍSTICA (BGE). Sinopse do Censo Demográfico de 2010. Rio de Janeiro: IBGE, 2011

LIMA FILHO, A.; MASSON, N.; COSTA, R. Atlas políticojurídico do trabalho escravo contemporâneo no Maranhão. Açailândia/Imperatriz: CDVDHCB/ETICA, 2011.

MANCINI, R. M. Siderurgia e mercado de trabalho na Amazônia maranhense: a dimensão socioeconômica da estruturação do território produtivo de Açailândia (MA). 2015. Dissertação (Mestrado em Ciências Sociais) Universidade Federal do Maranhão, São Luís.

MONTEIRO, M. A. Em busca do carvão vegetal barato: o deslocamento de siderúrgicas para a Amazônia. Novos Cadernos do NAEA, Belém, v.9, n.2, p.55-97, 2006.

MOURA, F. A. Escravos da Precisão: economia familiar e estratégias de sobrevivênciade trabalhadores rurais em Codó (MA). 2006. 121 p. Dissertação (Mestrado em Ciências Sociais) - Programa de Pós-graduação em Ciências Sociais da Universidade Federal do Maranhão, São Luís.

RAMALHO, J. R. Indústria e desenvolvimento: efeitos da reinvenção de um território produtivo no Rio de Janeiro. Revista Pós Ciências Sociais, São Luís, v. 12, n. 24, p.117140, 2015.

RAMALHO, J. R.; CARNEIRO, M. S. Ação sindical, contestação política e siderurgia na Amazônia brasileira. Novos Cadernos NAEA, Belém, v. 16, n. 1, p. 7-28, jun. 2013.

Trabalho e siderurgia na Amazônia brasileira. In: CARNEIRO, M. S.; RAMALHO, J. R. (Orgs.) Ações coletivas em complexos minero-metalúrgicos: experiências na Amazônia e no Sudeste brasileiro. São Luis: EDUFMA, 2015. 
REIS, J. Uma epistemologia do território. Estudos Sociedade e Agricultura, Rio de Janeiro, v. 13, n. 1, 2005 , p. 51-74. 2005.

SANTOS, R. S. P. A forja de Vulcano: siderurgia e desenvolvimento na Amazônia oriental e no Rio de Janeiro. 2010. Tese (Doutorado em Sociologia e Antropologia) Universidade Federal do Rio de Janeiro, Rio de Janeiro.

Redes de produção globais (RPGs): contribuições conceituais para a pesquisa em ciências sociais. Revista Pós Ciências Sociais, São Luís, n.15, p.127-141, 2011.

SANTOS, M. M. dos. A crise no setor siderúrgico do Distrito Industrial de Marabá e as estratégias empresariais. 2015. (Mestrado em Dinâmicas Territoriais e Sociedade na Amazônia) - Universidade Federal do Sul e Sudoeste do Pará, Marabá. 2015.
STEINER, P. A sociologia econômica. São Paulo: Atlas, 2006

SWEDBERG, R. Max Weber e a idéia de sociologia econômica. Rio de Janeiro: Editora UFRJ; São Paulo: Beca produções culturais, 2005. (Col. Economia e Sociedade, v.5)

TARROW, S. O poder em movimento: movimentos sociais e confronto político. Petrópolis, RJ: Vozes, 2009. 


\section{INDUSTRIAL DEVELOPMENT AND LABOUR MARKET: social contestation and recent transformations on siderurgical production in eastern Amazon}

\author{
Roberto Martins Mancini \\ Marcelo Sampaio Carneiro
}

\section{DEVELOPPEMENT INDUSTRIEL ET MARCHE DU TRAVAIL: protestation sociale et changements récents dans la production d'acier dans l'Amazonie}

\author{
Roberto Martins Mancini
}

Marcelo Sampaio Carneiro
This paper analyses the socioeconomic effects of a group of governmental politics of infrastructure and financial/tax subsidies (Programa Grande Carajás) that from the late 1970's had established a siderurgical zone for commodities production (pig iron) designed for exportation at the eastern Amazon area of Maranhão state. These governmental efforts trigged the emergence of a labour market around steel and forest workers, by the consequence of the use of charcoal as a input for siderurgical production. The analytic effort will be based on the theoretic paradigm of Global Production Networks, which stands as a multicentric approach that stresses the action of diversified social world actors to understand the process of configuration of that market, focusing the changes caused by the 2008's economic crisis, highlighting the role performed by trade unions, corporates and state agents in this process.

KEY-WORDS: Industrial development. Global production networks. Labour Market. Social criticismo. Amazon.
L'article vise à analyser les effets socio-économiques des politiques publiques d'infrastructure et des subventions fiscales (Programme Grand Carajás) établies à partir des anées 1970, pour la mise en œuvre d'un pôle industriel d'acier dans la l'Amazonie oriental brésilienne. Le développement de ces politiques gouvernementales a donné lieu à un marché de travail résultant des activités d'acier et la production de charbon de bois pour la production de fonte, marqueé pour la precarité, mais qui, au fil des années, a connu des changements remarquables. En utilisant l'approche des des réseaux mondiaux de production, perspective qui met l'accent multicentriques l'action des divers acteurs du monde social dans la formation de phénomènes économiques, nous cherchons à comprendre le processus de configuration du marché du travail, mettant en lumière les changements apportés par la crise mondiale de 2008 et le rôle joué par les syndicats, les employeurs et les agents de l'État dans ce processus.

Mots-CLÉs: Développement industriel. Réseaux internatiounaux de production. Marché du travail. Critique social. Amazonie.

Roberto Martins Mancini - Doutorando em Ciências Sociais pelo Programa de Pós-graduação em Ciências Sociais (PPGCsoc-UFMA). Desenvolve pesquisas através dos temas do desenvolvimento regional, territórios produtivos, mercado de trabalho e trajetórias ocupacionais. Recentemente publicou "A construção de uma experiência de economia solidária como alternativa à reprodução do trabalho escravo contemporâneo: o caso da Cooperativa para Dignidade do Maranhão de Açailândia/MA”. In: José Ricardo Ramalho; Marcelo Sampaio Carneiro (Orgs.). Ações Coletivas em complexos míneromatalúrgicos: experiências na Amazônia e no Sudeste brasileiro.

Marcelo Sampaio Carneiro - Doutor em Sociologia. Professor do Departamento de Sociologia e Antropologia e do Programa de Pós-Graduação em Ciências Sociais da UFMA. Desenvolve pesquisas na área de trabalho, economia e meio-ambiente. Publicações recentes: Terra, trabalho e poder: conflitos e lutas sociais no Maranhão contemporâneo. Annablume, 2013; Ações coletivas em complexos mínerometalúrgicos: experiências na Amazônia e no Sudeste brasileiro. EDUFMA, 2015 (organização com J. Ricardo Ramalho); Mercado e contestação: a atuação da crítica social e as transformações nas estratégias das empresas siderúrgicas de Carajás (1988-2012). Política e Sociedade, 2016; Le Brésil et l'environnement au XXIe siècle: des relations sous tensions. Revue Brésil(s), 2018 (em co-autoria com Julien Blanc). 
